\title{
Comparação de valores de energia metabolizável de alimentos determinados com frangos de corte e com codornas visando à formulação de dietas para codornas japonesas ${ }^{1}$
}

\author{
Marcelle Santana de Araujo², Sergio Luiz de Toledo Barreto², Paulo Cezar Gomes², Juarez \\ Lopes Donzele ${ }^{2}$, Eric Márcio Balbino², Matheus Henrique Valeriano ${ }^{2}$
}

\begin{abstract}
${ }^{1}$ Fonte financiadora: FAPEMIG
${ }^{2}$ Departamento de Zootecnia/UFV.

RESUMO - Foram utilizadas 648 codornas japonesas com produção de ovos de 91,1\% distribuídas em delineamento inteiramente ao acaso com nove repetições e oito aves por unidade experimental. As dietas foram avaliadas em arranjo fatorial $3 \times 3$ (alimento $\times$ formulação), por meio de medidas de desempenho das aves e de qualidade dos ovos. A interação entre alimento alternativo e formulação influenciou o consumo de ração; as demais variáveis (desempenho e características internas e externas dos ovos) não foram influenciadas pelos alimentos alternativos avaliados. O ganho de peso, a taxa de postura, o peso médio de ovo, a massa de ovo, a conversão alimentar por massa e a porcentagem de casca variaram de acordo com a formulação. Os valores de energia metabolizável aparente corrigida do milho, do sorgo, do farelo de soja e das farinhas de vísceras de aves, de carne e ossos e de peixe determinados em frangos de corte e em galinhas poedeiras não são apropriados para formulação de dietas para codornas japonesas.
\end{abstract}

Palavras-chave: Coturnix coturnix japonica, desempenho, nutrição, valor energético

\section{Comparison of metabolizable energy values of food determined with broilers and quails aiming at formulation of diets for Japanese quails}

\begin{abstract}
It was used 648 Japanese quails with 91.1\% of egg production in a completely randomized experiment design with nine replicates and eight birds per experimental unit. The diets were evaluated in a $3 \times 3$ factorial scheme (food $\times$ feed formulation) through bird performance measures and egg quality. The interaction among alternative food and formulation influenced feed intake. Both performance and internal and external egg traits were not affected by food alternative. Weight gain, laying rate, egg average weight, egg mass, feed conversion per mass and shell percentage varied according to the formulation. Values of corrected apparent metabolizable energy of corn, sorghum, soybean meal and poultry by product meal, meat and fish bones determined in broilers and laying hens are not suitable for formulation of diets for Japanese quails.
\end{abstract}

Key Words: Coturnix coturnix japonica, energy value, nutrition, performance

\section{Introdução}

Vários autores têm se dedicado às pesquisas na área de nutrição e avaliação do conteúdo energético de alimentos para codornas (Fioravanti et al., 2004, Sakamoto et al., 2006; Santos et al, 2006; Gomes et al., 2007; Oliveira, 2007; Soares et al., 2007; Rezende et al., 2009), porém ainda há escassez de dados, principalmente em comparação aos obtidos com frangos e galinhas. A limitação dessas informações prejudica a elaboração de dietas para máxima lucratividade e desempenho na coturnicultura. De acordo com Sibbald (1980), a correta formulação das dietas depende da precisão da determinação dos valores de energia metabolizável (EM). Portanto, conhecer o valor energético é de extrema importância, pois a energia útil do alimento depende também do animal que o consome, e não exclusivamente do alimento (Penz Júnior et al., 1999).

Além da espécie e da idade do animal, outros fatores, como o tipo de processamento e a ausência de padrão dos componentes, podem ocasionar variação nos valores de energia metabolizável encontrados na literatura para o mesmo alimento, principalmente se a avaliação for referente a subprodutos de origem animal.

A valorização nutricional dos resíduos potencialmente poluidores do meio ambiente em matérias-primas utilizadas na alimentação de monogástricos, além de ajudar na solução 
de problemas ambientais, permite reduzir os custos de produção (Nascimento et al., 2005; Nunes et al., 2005; Generoso et al., 2008).

As dietas destinadas à alimentação de codornas são frequentemente balanceadas empregando-se valores de energia metabolizável que, de acordo com Rostagno et al. (2005), foram determinados com pintos, galos e galinhas poedeiras. Contudo, essa pode ser considerada uma extrapolação incorreta (Murakami \& Furlan, 2002), pois codornas possuem maior taxa de passagem dos alimentos no trato digestivo e maior proporção do aparelho digestivo em relação ao peso corporal. Esse fato pode gerar diferenças na digestibilidade, no aproveitamento e na determinação do valor energético dos alimentos.

Objetivou-se com esta pesquisa avaliar resultados de desempenho e de qualidade de ovos de codornas japonesas em fase de produção alimentadas com dietas formuladas utilizando-se alimentos cujos valores de energia metabolizável aparente corrigida (EMAn) foram determinados para codornas e comparar dietas formuladas utilizando-se a EMAn dos alimentos determinada em frangos de corte e galinhas poedeiras.

\section{Material e Métodos}

O experimento foi desenvolvido no setor de avicultura da Universidade Federal de Viçosa, Minas Gerais, no período de 29 de junho a 22 de setembro de 2008.

Foram utilizadas 648 codornas japonesas com 82 dias de idade, produção média de ovos de 91,1\% e peso médio inicial de 178,09 \pm 4,34 g, distribuídas em delineamento inteiramente ao acaso, em arranjo fatorial $3 \times 3$ (alimentos $\times$ formulações), com nove repetições e oito aves por unidade experimental. Os alimentos alternativos avaliados foram farinha de vísceras de aves, farinha de carne e ossos e farinha de peixe; e as formulações comparadas foram dieta utilizando alimentos cujos valores de EMA foram determinados com pintos, galos e galinhas poedeiras (Rostagno et al., 2005); dieta formulada com valores de EMA determinados para codornas (Araújo, 2008); e a terceira formulação foi uma dieta controle.

As dietas experimentais (Tabela 1 ) foram formuladas à base de milho, farelo de soja e sorgo, atendendo às exigências nutricionais utilizadas por Lima et al. (2010). O inerte (areia lavada) foi adicionado para completar a quantidade de ração sem interferir nos nutrientes. A composição química e os níveis práticos de inclusão dos alimentos foram aqueles preconizados por Rostagno et al. (2005), com exceção das dietas cujas formulações (utilizadas como fonte de comparação dos valores de EM dos alimentos) foram calculadas com valor de energia metabolizável dos alimentos determinados para codornas.

Objetivando maior precisão na comparação entre os resultados obtidos com o uso das dietas, duas das dietas foram calculadas utilizando-se valores subótimos de energia metabolizável, de $2.600 \mathrm{kcal}$ de EM/kg de dieta. A dieta controle continha, por quilograma, $2.800 \mathrm{kcal}$ de EM, e atendia à exigência em energia metabolizável das codornas (Lima et al., 2010). A dieta controle foi incluída com a finalidade de se ter como parâmetro um padrão de desempenho, ou seja, uma dieta que proporcionasse máximo desempenho às aves que receberam conteúdo de energia metabolizável adequado às suas exigências. Dessa forma, as demais dietas (ambas com níveis subótimos de energia metabolizável) puderam ser comparadas entre si, tornando possível também determinar qual promoveu desempenho animal e qualidade dos ovos mais próximos do obtido com a dieta controle.

Considerando que a densidade energética da dieta influencia na ingestão de alimentos pelas aves, o consumo foi controlado. O consumo diário foi estimado previamente ao período experimental. Durante o experimento, a dieta era pesada e armazenada em sacos plásticos, em peso equivalente à quantidade de aves da gaiola (unidade experimental) por dia e, portanto, corrigido para o número de aves mortas. As sobras foram recolhidas ao final de cada dia, pesadas e anotadas, para posterior cálculo da média de consumo das dietas.

As gaiolas utilizadas eram dispostas em sistema escada de dois andares confeccionadas em arame, com dimensões de $25 \times 34 \times 16 \mathrm{~cm}$ (largura $\times$ profundidade $\times$ altura) equipadas com comedouro linear de metal galvanizado, bebedouro automático tipo nipple e aparador de ovos.

O programa de luz adotado forneceu fotoperíodo com duração diária de 16h, foram utilizadas lâmpadas incandescestes de $60 \mathrm{~W}$ controladas por temporizador analógico (timer). Diariamente, a coleta dos ovos foi realizada pela manhã (às $8 \mathrm{~h}$ ) e o fornecimento das dietas no período da manhã (às 8 h) e à tarde (às 16 h).

As medidas de desempenho das aves avaliadas foram consumo de ração (g), ganho de peso (g), taxa de postura (\%), peso médio do ovo (g), massa de ovos (g) e conversão alimentar por massa de ovos e as de qualidade interna e externa dos ovos, porcentagem de gema, de albúmen e de casca e gravidade específica.

O peso médio dos ovos foi obtido por meio da pesagem de todos os ovos íntegros produzidos dividido pelo número de ovos de cada unidade experimental. Para determinação da gravidade específica, mergulharam-se todos os ovos íntegros de cada unidade experimental em soluções salinas 
Tabela 1 - Composição das dietas experimentais

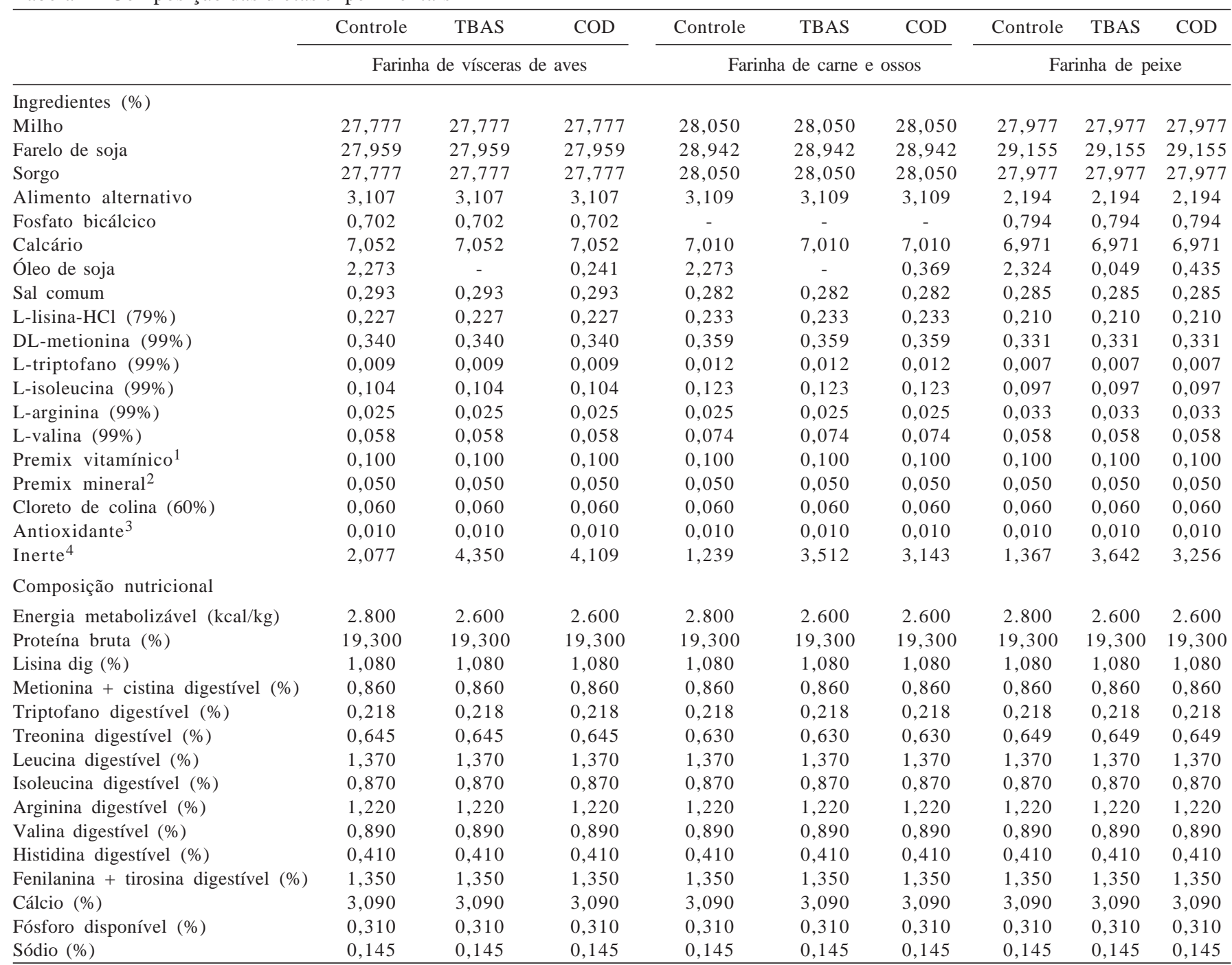

TBAS = Tabelas Brasileiras para Aves e Suínos, EMAn dos alimentos determinada com pintos, galos e galinhas poedeiras, segundo Rostagno et al. (2005).

COD = EMAn dos alimentos determinada com codornas japonesas (Araujo, 2008).

${ }^{1}$ Composição/kg de produto: vit. A - 12.000 .000 U.I.; vit. $\mathrm{D}_{3}$ - 3.600.000 U.I.; vit. E - 3.500 U.I.; vit $\mathrm{B}_{1}$ - 2.500 mg; vit. $\mathrm{B}_{2}$ - 8.000 mg; vit. $\mathrm{B}_{6}$ - 5.000 mg; ácido pantotênico -

12.000 mg; biotina - 200 mg; vit. K - 3.000 mg; ácido fólico - 1.500 mg; ácido nicotínico - 40.000 mg; vit. B 12 - 20.000 mg; Se - 150 mg; veículo q.s.p. - 1.000 g.

2 Composição/kg de produto: Mn - 160 g; Fe - 100 g; Zn - 100 g; Cu - 20 g; Co - 2 g; I - 2 g; excipiente q.s.p. - 1.000 g.

3 Butil-hidróxi-tolueno (99\%).

${ }^{4}$ Areia lavada.

com densidade variando de 1,050 a $1,085 \mathrm{~g} / \mathrm{cm}^{3}$, com diferença de $0,005 \mathrm{~g} / \mathrm{cm}^{3}$ entre elas, para posterior cálculo da média ponderada. As soluções foram calibradas com o auxílio de densímetro modelo INCOTERM - OM - 5565. O peso relativo dos componentes (porcentagem de casca, de albúmen e de gema) foi obtido de quatro ovos de cada unidade experimental, dividindo-se o peso absoluto do componente pelo peso do ovo inteiro. Essas variáveis foram analisadas a cada 21 dias durante três dias consecutivos, enquanto o peso dos ovos e dos componentes foi avaliado nos dias 19, 20, 21, 40, 41, 42, 61, 62, 63, 82, 83 e 84 e a gravidade específica nos dias 16, 17, 18, 37, 38, 39, $58,59,60,79,80$ e 81 do período experimental. As demais variáveis foram calculadas para todo período experimental a partir de dados observados diariamente.
Os valores de proteína bruta e energia bruta dos alimentos utilizados nas dietas experimentais foram analisados no Laboratório de Nutrição Animal do Departamento de Zootecnia da Universidade Federal de Viçosa, Minas Gerais.

O valor de energia metabolizável aparente corrigida (EMAn) de cada alimento (Tabela 2) foi calculado a partir do coeficiente de metabolizabilidade da energia bruta (CMEBn), de acordo com a fonte de dados utilizada como objeto de comparação, ou seja, para EMAn determinada com pintos, galos e galinhas poedeiras, utilizaram-se dados de Rostagno et al. (2005) e, para EMAn determinada para codornas japonesas, utilizaram-se resultados (CMEBn), segundo Araujo (2008), identificados como TBAS e COD, respectivamente. 
Tabela 2 - Proteína e energia bruta, coeficiente de metabolizabilidade dos alimentos e energia metabolizável aparente corrigida dos alimentos utilizados nas dietas experimentais, com base na matéria natural

\begin{tabular}{|c|c|c|c|c|c|c|c|c|}
\hline \multirow[t]{2}{*}{ Alimento } & \multicolumn{2}{|c|}{ Proteína bruta (\%) } & \multicolumn{2}{|c|}{ Energia bruta (kcal/ kg) } & \multicolumn{2}{|c|}{ CMEBn (\%) } & \multicolumn{2}{|c|}{ EMAn (kcal/kg) } \\
\hline & TBAS & LNA & TBAS & LNA & TBAS & COD & TBAS & COD \\
\hline Milho & 8,26 & 7,75 & 3.925 & 3.933 & 86,14 & 84,30 & 3.387 & 3.315 \\
\hline Sorgo & 9,23 & 10,25 & 3.928 & 3.967 & 81,26 & 80,66 & 3.224 & 3.200 \\
\hline Farelo soja & 45,32 & 45,43 & 4.079 & 4.304 & 55,31 & 54,74 & 2.380 & 2.356 \\
\hline Farinha de carne e ossos & 41,00 & 40,79 & 3.286 & 3.098 & 58,95 & 60,51 & 1.826 & 1.875 \\
\hline Farinha de vísceras e aves & 57,00 & 53,34 & 4.661 & 4.520 & 69,92 & 78,64 & 3.160 & 3.554 \\
\hline$\underline{\text { Farinha de peixe }}$ & 54,40 & 53,59 & 4.114 & 3.708 & 63,85 & 64,09 & 2.368 & 2.376 \\
\hline
\end{tabular}

CMEBn = coeficiente de metabolizabilidade; EMAN = energia metabolizável aparente corrigida; TBAS = Tabelas Brasileiras para Aves e Suínos, valores segundo Rostagno et al. (2005); COD = valores segundo Araujo (2008); LNA = análises realizadas no Laboratório de Nutrição Animal DZO/UFV.

A análise de variância foi realizada para todas variáveis e as médias comparadas pelo teste Tukey a 5\% de probabilidade, utilizando-se o programa SAEG - Sistema de Análise Estatística e Genética (UFV, 2005).

\section{Resultados e Discussão}

Com base nos valores observados para os parâmetros ambientais (Tabela 3), o ambiente pode ser classificado como confortável para as aves e não influenciou os resultados. De acordo com Oliveira et al. (2005), a combinação dos valores de temperatura de bulbo seco na faixa de 20 a $30^{\circ} \mathrm{C}$ e 12 a $25^{\circ} \mathrm{C}$ com os de umidade relativa abaixo de $70 \%$ e entre 75 e $80 \%$, respectivamente, podem ser classificados como de conforto térmico bom para poedeiras em fase de produção.

O consumo de ração foi a única característica de desempenho influenciada $(\mathrm{P}<0,01)$ pela interação entre formulação e alimento alternativo (Tabela 4). Também foi afetado $(P<0,05)$ pelos alimentos alternativos utilizados na dieta, uma vez que as codornas mantidas com a dieta contendo farinha de carne e ossos consumiram menos que aquelas alimentadas com as dietas que continham farinha de vísceras de aves e/ou farinha de peixe. No entanto, o consumo de ração não foi influenciado $(\mathrm{P}>0,05)$ nas demais dietas; o valor determinado com o uso de farinha de peixe foi numericamente semelhante ao obtido com o uso de farinha de vísceras de aves e superior ao obtido com farinha de carne e ossos.

Os alimentos alternativos estudados não influenciaram ( $\mathrm{P}>0,05)$ o desempenho das aves nem o peso médio de ovo, porém as formulações utilizadas provocaram efeitos contrários nos parâmetros avaliados.

A dieta formulada com base nos valores de EMAn determinados com codornas proporcionou maior ganho de peso, ou seja, promoveu ganho de peso superior àquele obtido com a dieta formulada com base nos valores determinados com frangos de corte. Além disso, o ganho de peso das codornas alimentadas com dieta formulada utilizando-se os valores de EMAn determinados com a mesma espécie foi semelhante $(\mathrm{P}<0,05)$ ao do grupo controle.

A dieta controle possibilitou às aves melhores resultados $(\mathrm{P}<0,01)$ para taxa de postura, peso médio do ovo, massa do ovo e conversão alimentar por massa. Desse modo, as comparações a seguir serão feitas entre aves que foram alimentadas com as duas dietas formuladas com níveis subótimos de energia metabolizável para codornas.

A taxa de postura e a massa de ovos (Tabela 4) entre as codornas alimentadas com dieta formulada com valores de EMAn determinados para codornas foram superiores em 3,26 e 3,19\%, respectivamente, às médias obtidas com a dieta formulada com valores determinados em frangos. Silva et al. (2003), apesar de não terem encontrado resposta significativa para as variáveis estudadas, notaram superioridade (6,5\%), em valores absolutos, na produção de ovos de codornas alimentadas com uma dieta formulada considerando o conteúdo energético do milho e do farelo de soja estimado por Furlan et al. (1996) em codornas japonesas, em comparação a uma dieta balanceada com base nos dados obtidos para frangos de corte.

Tabela 3 - Temperaturas mínima, máxima, de bulbo seco e de bulbo úmido e umidade relativa do ar durante o período experimental

\begin{tabular}{lccccc}
\hline Hora & Mínima $\left({ }^{\circ} \mathrm{C}\right)$ & Máxima $\left({ }^{\circ} \mathrm{C}\right)$ & Bulbo seco $\left({ }^{\circ} \mathrm{C}\right)$ & Bulbo úmido $\left({ }^{\circ} \mathrm{C}\right)$ & Umidade \\
\hline $8 \mathrm{~h}$ & & $17,87 \pm 2,98$ & $15,27 \pm 2,12$ & $76,14 \pm 9,72$ \\
$16 \mathrm{~h}$ & $15,53 \pm 2,89$ & $26,75 \pm 3,28$ & $23,29 \pm 3,36$ & $17,39 \pm 2,24$ & $59,51 \pm 12,36$ \\
\hline
\end{tabular}


Tabela 4 - Desempenho das aves e peso médio de ovo de acordo com as formulações e com os alimentos alternativos

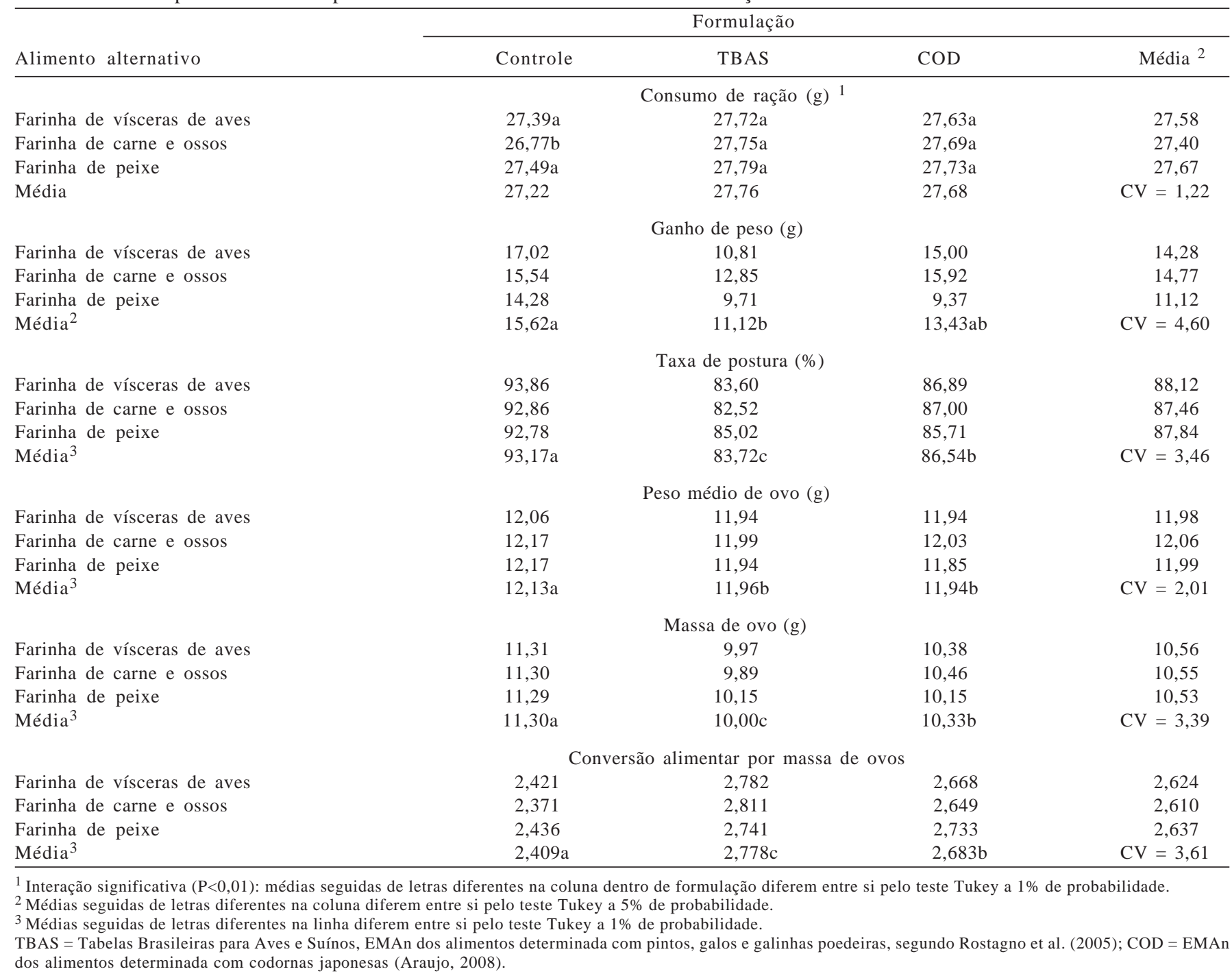

O valor de conversão alimentar (Tabela 4) obtido com a dieta formulada para codornas foi menor em 3,6\% àquele observado com a dieta para frangos. Da mesma maneira, Silva et al. (2003) detectaram diferenças numéricas, em relação aos resultados obtidos com as diferentes formulações usadas para codornas, ou seja, a dieta cujo valor energético dos alimentos foi determinado com aves de mesma espécie melhorou em $12 \%$ a conversão alimentar por massa de ovo em relação à dieta formulada com a energia do milho e do farelo de soja determinada com frangos de corte.

Para peso médio dos ovos (Tabela 4), verificou-se efeito não-significativo $(\mathrm{P}>0,05)$ para aqueles provenientes de aves alimentadas com dieta formulada com base nos valores energéticos de alimentos determinados para codornas e para frangos de corte.
Observou-se interação não-significativa $(\mathrm{P}>0,05)$ entre a formulação e o alimento alternativo e não houve efeito significativo $(\mathrm{P}>0,05)$ dos alimentos sobre as variáveis estudadas. Contudo, a formulação das dietas influenciou as variáveis relacionadas à qualidade de casca $(\mathrm{P}<0,01)$. A porcentagem de casca e a gravidade específica dos ovos (Tabela 5) foram maiores para codornas alimentadas com dieta controle, ou seja, independentemente da fonte de dados, os resultados foram semelhantes entre as dietas. A observação dos valores de qualidade externa dos ovos de codornas indica que valores de EMAn dos alimentos podem ser utilizados na nutrição de codornas independentemente da fonte de dados, ou seja, os valores descritos em tabelas para frangos de corte ou aqueles determinados com codornas não proporcionaram diferenças estatísticas para essas características. 
Tabela 5 - Qualidade interna e externa de ovos de codornas japonesas de acordo com as formulações e os alimentos alternativos

\begin{tabular}{|c|c|c|c|c|}
\hline \multirow[b]{2}{*}{ Alimento } & \multicolumn{3}{|c|}{ Formulação } & \multirow[b]{2}{*}{ Média 2} \\
\hline & Controle & TBAS & COD & \\
\hline \multicolumn{5}{|c|}{ Gema (\%) } \\
\hline Farinha de vísceras de aves & 29,42 & 29,61 & 29,47 & 29,50 \\
\hline Farinha de peixe & 29,51 & 29,48 & 29,82 & 29,60 \\
\hline Média & 29,51 & 29,70 & 29,51 & $\mathrm{CV}=1,96$ \\
\hline Farinha de carne e ossos & 62,26 & 61,93 & 62,72 & 62,30 \\
\hline Farinha de peixe & 62,39 & 62,52 & 62,22 & 62,38 \\
\hline Média & 62,35 & 62,33 & 62,53 & $\mathrm{CV}=1,08$ \\
\hline \multicolumn{5}{|c|}{ Casca (\%) } \\
\hline Farinha de vísceras de aves & 8,18 & 7,86 & 7,86 & 7,97 \\
\hline Farinha de carne e ossos & 8,13 & 8,05 & 8,01 & 8,06 \\
\hline Farinha de vísceras de aves & 1,0737 & 1,0717 & 1,0725 & 1,0726 \\
\hline Farinha de carne e ossos & 1,0741 & 1,0730 & 1,0727 & 1,0733 \\
\hline Farinha de peixe & 1,0743 & 1,0728 & 1,0728 & 1,0733 \\
\hline Média 1 & $1,0740 \mathrm{a}$ & $1,0725 b$ & $1,0727 \mathrm{~b}$ & $\mathrm{CV}=0,14$ \\
\hline
\end{tabular}

${ }^{1}$ Médias seguidas por letras diferentes na linha diferem entre si pelo teste Tukey a $1 \%$

TBAS = Tabelas Brasileiras para Aves e Suínos, EMAn dos alimentos determinada com pintos, galos e galinhas poedeiras, segundo Rostagno et al. (2005); COD = EMAn dos alimentos determinada com codornas japonesas (Araujo, 2008)

\section{Conclusões}

Os valores de energia metabolizável aparente corrigida do milho, do sorgo, do farelo de soja e das farinhas de vísceras de aves, de carne e ossos e de peixe determinados com codornas japonesas proporcionam melhor desempenho quando utilizados na formulação de dietas destinadas à alimentação de codornas japonesas em postura em comparação a dietas formuladas com base no valor de energia metabolizável aparente corrigida determinado com pintos, galos e/ou galinhas poedeiras. Contudo, parâmetros ligados à qualidade interna e externa dos ovos de codornas japonesas não são influenciados pelos valores de energia metabolizável aparente corrigida dos alimentos.

\section{Agradecimentos}

À Fundação de Amparo à Pesquisa do Estado de Minas Gerais - FAPEMIG, pelo financiamento do projeto de pesquisa.

\section{Referências}

ARAUJO, M.S. Composição química e energética e aminoácidos digestíveis de alguns alimentos para codornas japonesas. 2008. 76f. Dissertação (Doutorado em Zootecnia) - Universidade Federal de Viçosa, Viçosa, MG.

FIORAVANTI, W.; GOMES, F.A.; FASSANI, E.J. Valores energéticos de alguns alimentos protéicos utilizados em rações de codornas japonesas (Coturnix coturnix japonica). In: SEMIC SEMINÁRIO DE INICIAÇÃO CIENTÍFICA DA UNIFENAS, 3., 2004, Alfenas. Anais eletrônicos... Alfenas: Universidade José do Rosário Vellano - ANIFENAS, 2004. Disponível em: <http://www.unifenas.br/pesquisa/semic/iiisemic/anais/trab/ Zootecnia/resumos/zoot5.PDF>. Acesso em: 10/1/2008.

FURLAN, A.C.; ANDREOTTI, M.O.; MURAKAMI, A.E. et. al. Valores energéticos de alguns alimentos determinados com codornas japonesas (Coturnix coturnix japonica) In CONFERÊNCIA APINCO DE CIÊNCIA E TECNOLOGIA AVÍCOLAS, 1996, Campinas. Anais... Campinas: FACTA, 1996. p.43.

GENEROSO, R.A.R.; GOMES, P.C.; ROSTAGNO, H.S. et al. Composição química e energética de alguns alimentos para frangos de corte em duas idades. Revista Brasileira de Zootecnia, v.37, n.7, p.1251-1256, 2008.

GOMES, F.U.; FASSANI, E.J.; RODRIGUES, P.B. et al. Valores energéticos de alguns alimentos utilizados em rações para codornas japonesas. Revista Brasileira de Zootecnia, v.36, n.2, p.396-402, 2007.

LIMA, H.J.D.; BARRETO, S.L.T.; ALBINO, L.F.T. et al. Aproveitamento de nutrientes e de energia da ração de codornas japonesas em postura com o uso de fitase. Revista Brasileira de Zootecnia, v.39, n.7, p.1517-1522, 2010.

MURAKAMI, A.E.; FURLAN, A.C. Pesquisas na nutrição e alimentação de codornas em postura no Brasil. In: SIMPÓSIO INTERNACIONAL DE COTURNICULTURA， 1., 2002, Lavras. Anais... Lavras: Universidade Federal de Lavras, 2002. p.113-120.

NASCIMENTO, G.A.J.; COSTA, F.P.G.; AMARANTE JÚNIOR, V.S. et al. Efeitos da substituição do milho pela raspa de mandioca na alimentação de frangos de corte, durante as fases de engorda e final. Revista Ciência e Agrotecnologia, v.29, n.1, p.200-207, 2005.

NATIONAL RESERCH COUNCIL - NRC. Nutrient requirements of poultry. 9.ed. Washington: National Academy of Sciences, 1994. p.155. 
NUNES, R.V.; POZZA, P.C.; NUNES, C.G.V. et al. Valores energéticos de subprodutos de origem animal para aves. Revista Brasileira de Zootecnia, v.34, n.4, p.1217-1224, 2005.

OLIVEIRA, B.L. Manejo em granjas automatizadas de codornas de postura comercial. In: SIMPÓSIO INTERNACIONAL, 3.; CONGRESSO BRASILEIRO DE COTURNICULTURA, 2., 2007, Lavras. Anais... Lavras: Universidade Federal de Lavras, 2007. p.11-16.

OLIVEIRA, H.L.; AMENDOLA, M.; NÄÄS. I.A. Estimativa das condições de conforto térmico para avicultura de postura usando a teoria dos conjuntos fuzzy. Revista de Engenharia Agrícola, v.25, n.2, p.300-307, 2005.

PENZ JUNIOR, A.M. Novos conceitos de energia para aves. In: SIMPÓSIO INTERNACIONAL SOBRE NUTRIÇÃO DE AVES, 1999, Campinas. Anais... Campinas: FACTA, 1999. p.1-24.

REZENDE, M.J.M.; TORRES, A.F.; MURATA, L.S. et al. Determination of metabolizable energy value of corn with different average geometric diameters for european quails (Coturnix coturnix coturnix) Brazilian Archives of Biology and Technology, v.52, n.4, p.981-984, 2009.

ROSTAGNO, H.S. Tabelas brasileiras para aves e suínos: composição de alimentos e exigências nutricionais. 2.ed. Viçosa, MG: UFV, Departamento de Zootecnia, 2005. 186p.
SAKAMOTO, M.I.; MURAKAMI, A.E.; SOUZA, L.M.G. et al. Valor energético de alguns alimentos alternativos para codornas japonesas. Revista Brasileira de Zootecnia, v.35, n.3, p.818-821, 2006.

SANTOS, A.L.S.; GOMES, A.V.C.; PESSOA, M.F. et al. Composição química e valores energéticos de fontes protéicas em codornas de corte em diferentes idades. Revista Ciência Rural, v.36, n.3, p.930-935, 2006.

SIBBALD, I.R. Metabolizable energy in poultry nutrition. Bio Science, v.30, p.736-741, 1980.

SILVA, J.H.V.; SILVA, M.B.; SILVA, E.L. et al. Energia metabolizável de ingredientes determinada com codornas japonesas (Coturnix coturnix japonica). Revista Brasileira de Zootecnia, v.32, n.6, p.1912-1918, 2003 (supl. 2).

SOARES, M.B.; FUENTE, F.M.F.; FREITAS, E.R. et al. Farelo de amêndoa da castanha de caju na alimentação de codornas japonesas na fase de postura. Revista Brasileira de Zootecnia, v.36, n.4, p.1076-1082, 2007.

UNIVERSIDADE FEDERAL DE VIÇOSA - UFV. Central de Processamento de Dados - UFV/CPD. SAEG - Sistema para análises estatísticas. Versão 9.1. Viçosa, MG, 2005. $301 p$. 